\title{
In Drinking Water/Milk Use Route of Administration
}

National Cancer Institute

\section{Source}

National Cancer Institute. In Drinking Water/Milk Use Route of Administration. NCI

Thesaurus. Code C149574.

Administration of a veterinary medicinal product by incorporation into the animal drinking water, milk or milk replacer.C238 